\title{
Analysis of the experience of the geriatric fracture program in two institutions in Colombia: a reproducible model?
}

\section{Análisis de la experiencia de un programa de adulto mayor fracturado en dos instituciones en Colombia: ¿un modelo reproducible?}

\author{
Carlos Mario Olarte, ${ }^{1,2}$ Mauricio Zuluaga, ${ }^{3}$ Adriana Guzman. ${ }^{3}$ Julian Camacho, ${ }^{1}$ \\ Pieralessandro Lasalvia, ${ }^{4}$ (D) Nathaly Garzon, ${ }^{4}$ (D) Laura Prieto, ${ }^{4}$ Carmen Elisa Nuñez, ${ }^{5}$ Jose \\ Acuña, ${ }^{5}$ Alejandro Mejía, ${ }^{1}$ (D) Maria Claudia García ${ }^{3}$ \\ plasalvia@neuroeconomix.com
}

1 Fundación Santa Fe de Bogotá, Bogotá, Colombia. 2 Hospital Infantil Universitario de San José, Bogotá, Colombia, 3 Centro Médico Imbanaco, Cali, Colombia, 4 NeuroEconomix, Bogotá, Colombia, 5 Johnson \& Johnson, Bogotá, Colombia.

Citation: Olarte CM, Zuluaga M, Guzmán A, Camacho J, Lasalvia P, Garzon N, Prieto L, Nuñez CE, Acuña J, Mejía A, García MC. Analysis of the experience of the geriatric fracture program in two institutions in Colombia: a reproducible model?. Colomb Méd (Cali), 2021;

52(3):e2034524 http://doi. org/10.25100/cm.v52i 3.4524

Received: 31 Aug 2020

Revised: 03 Mar 2021

Accepted : 05 May 2021

Published: 12 Jun 2021

Keywords:

Geriatric fracture program, health services for the aged, Fractures, bone, health plan implementation

Palabras clave:

Programa fracturas geriatricas, servicios de salud para ancianos, fracturas, hueso, implementación de un plan en salud.

\section{Abstract}

\section{Background:}

hip fracture is the major cause of morbidity and mortality. Geriatric fracture programs promise to improve the quality of care, health outcomes and reduce costs.

\section{Objective:}

To describe the results related to the Geriatric fracture programs implementation in two Colombian institutions to assess reproducibility.

\section{Methods:}

We performed A retrospective descriptive study of the patients treated under the Geriatric fracture programs in two institutions in Colombia. The information was collected from the initial year of implementation until 2018. Demographic characteristics, length of stay, hospitalization complications, readmissions and mortality were described. Consumption of healthcare resources was defined using base cases determined with local experts and costs were estimated using standard methods.

\section{Results:}

475 patients were included in the Geriatric fracture programs. We observed an increase in the number of patients. The length of stay decreased between $8.5 \%$ and $26.1 \%$ as did the proportion of total complications, with delirium having the greatest reduction. A similar situation was seen for first year mortality (from $10.9 \%$ to $4.7 \%$ ), in-hospital deaths and readmissions. Estimates of costs of stay and complications showed reductions in all scenarios, varying between $22 \%$ and $68.3 \%$. 
Copyright: @ 2021 Universidad del Valle (c) (1) $(5)$

\section{Conflicts of interest:}

Carmen Elisa Nuñez and Jose Acuña were current Johnson \& Johnson Colombia employees during this study. Other authors do not declare any conflict of interest.

Funding:

This study received funding by Johnson \& Johnson Colombia.

Corresponding author:

Pieralessandro Lasalvia, Carrera 13 \# 101-32, apto 502, Bogotá, Colombia. Phone: (+57) 314-216-8897. E-mail: plasalvia@neuroeconomix.com

\section{Conclusions:}

The present study presents the experience of two institutions that implemented the Geriatric fracture programs with increase in the number of patients treated and reductions in the time of hospital stay, the proportion of complications, readmissions, mortality and estimated costs. These are similar between both institutions and with other published implementations. This could hint that geriatric fracture program may be implemented with reproducible results.

\section{Resumen}

\section{Antecedentes:}

las fracturas de cadera son una causa importante de morbilidad y mortalidad. Los programas de fracturas geriátricas prometen mejorar la calidad de la atención, los desenlaces clínicos y reducir costos,

\section{Objetivos:}

Describir los resultados relacionados con la implementación de un programa de fracturas geriátricas en dos instituciones en Colombia para evaluar la reproducibilidad

\section{Métodos:}

Realizamos un estudio retrospectivo descriptivo de los pacientes atendidos en el programa de fracturas geriátricas en dos instituciones en Colombia. Se obtuvo información desde el año de implementación hasta 2018. Se describió información demográfica, de estancia hospitalaria, de complicaciones, de rehospitalizaciones y de mortalidad. Se determinó un caso base de consumo de recursos con expertos y se costeó usando métodos estandarizados.

\section{Resultados:}

Se incluyeron 475 pacientes. Se observó un aumento en la cantidad de pacientes. La duración de estancia disminuyó entre $8.5 \%$ y $26.1 \%$, así como la frecuencia de complicaciones. Se encontraron reducciones en mortalidad en el primer año (entre $10.9 \%$ y $4.7 \%$ ), muertes hospitalarias y rehospitalizaciones. Los costos estimados mostraron reducciones entre $22 \%$ y $68.3 \%$.

\section{Conclusiones:}

El presente estudio muestra la experiencia de implementación de programa de fracturas geriátricas en dos instituciones en Colombia, mostrando aumento en cantidades de pacientes y reducciones en estancia hospitalaria, frecuencia de complicaciones, rehospitalizaciones, mortalidad y costos estimados. Los resultados fueron similares en las dos instituciones y comparables con otros descritos en literatura. Esto sugiero que los programas de fracturas geriátricas se pueden implementar con resultados reproducibles. 


\section{Remark}

\section{1) Why was this study conducted?}

To describe the results related to the Geriatric fracture programs implementation in two Colombian institutions to assess reproducibility.

\section{2) What were the most relevant results of the study?}

The present study presents the experience of two institutions that implemented the Geriatric fracture programs with increase in the number of patients treated and reductions in the time of hospital stay, the proportion of complications, readmissions, mortality and estimated costs.

\section{3) What do these results contribute?}

Both institutions showed positive results from program implementation. These are similar between both institutions and with other published implementations. This could hint that geriatric fracture program may be implemented with reproducible results.

\section{Introduction}

Hip fractures are considered a worldwide health problem ${ }^{1}$, as they are associated with high mortality and morbidity rates ${ }^{2,3}$. Demographic changes have increased the incidence of this type of fracture, which increases exponentially with age ${ }^{4,5}$. Likewise, the highest mortality rates occur in the elderly, with an annual mortality of $8 \%$ to $26 \%$ and greater values for patients over 80 years with hip fracture ${ }^{6}$.

In recent years the incidence of hip fracture has increased in several Latin American countries. Aziziyeh R et al , estimated by 2020 an increase in the number of hip fractures in adults between 50 and 89 years of $7.3 \%, 17 \%, 19.1 \%$ and $15.3 \%$ in Argentina, Brazil, Colombia and Mexico, respectively, due to the aging population.

In Colombia, osteoporosis and hip fractures result in high morbidity and mortality. Its prevalence increases dramatically after the age of 50 and its management requires, in most cases, surgical intervention. These fractures are related to a deterioration in the quality of life, disability, higher mortality and a high $\operatorname{cost}^{8}$. The estimated annual cost for osteoporosis-related fractures in Mexico, Argentina, Brazil and Colombia is 411, 360, 310 and 94 million dollars, respectively ${ }^{7}$. Several studies have shown that between $44 \%$ and $57 \%$ of the total hospital cost is associated with hip fracture care ${ }^{9-11}$.

Due to the above, comprehensive care programs have been developed worldwide, called geriatric fracture programs. These programs are defined by a multidisciplinary joint management system, early surgical intervention, patient-centered care using standardized protocols, and early discharge planning to reduce the length of hospital stay ${ }^{12,13}$. Their objectives are to improve the quality of care, health outcomes and reduce costs. These programs have shown various positive effects for patients, professionals and health systems ${ }^{14,15}$. In 2008, a geriatric fracture program was implemented at the University Children's Hospital of San José in Bogotá. They showed reductions in mortality and hospital stay in 298 patients in the program in the initial four years of implementation ${ }^{16}$.

The objective of this study was to describe the results related to the implementation of 
geriatric fracture programs in two Colombian health institutions. The end goal is to compare them with previous implementation of geriatric fracture programs in Colombia to assess reproducibility. If similar positive results can be achieved when implementing the program in other institutions, this could hint to reproducibility of the model.

\section{Materials and Methods}

A retrospective descriptive study was carried out using information from patients older than 65 years who had fractures resulting from fragility, who were treated in two health institutions that recently implemented geriatric fracture programs. These institutions are highly complex institutions with long-term care programs for fracture patients. Institution A is in Bogota and had 230 general inpatient, 5 intermediate care and 21 intensive care beds for adults. Institution B is in Cali had 168 general inpatient, 17 intermediate care and 31 intensive care beds for adults.

\section{Geriatric fracture program description}

The implemented model is based on the Rochester orthopedic management model ${ }^{12}$, which has been previously implemented in another institution in Colombia ${ }^{16}$. In summary, the model is a multidisciplinary joint management system to produce a comprehensive care plan. Target patients were at least 65 years of age and suffered from hip fracture requiring surgical intervention. The program considered two components (Figure 1S). The first one was related to inpatient care. This phase was triggered whenever a target patient was admitted though the Emergency Room and was referred to the orthopedics and geriatrics services. They defined the initial diagnosis, appropriate treatment according to patient status and fracture type, and initial rehabilitation strategies. The second component considered outpatient care during the first postsurgical year. Orthopedics controls were performed at 15 days, 1 month, 3 months, 6 months and 12 months after surgical intervention and focused on rehabilitation and osteoporosis treatment. Additional follow ups could be scheduled if necessary. Geriatrics consultations were also performed, focusing on general health status, comorbidity management, functionality assessments, fall prevention and osteoporosis treatment. Scheduling for geriatric care was defined on a per-case base depending on individual situation and evolution.

One of the model's objectives were to minimize the time before and after the surgical procedure, reducing the total time of stay. In this way, was is expected that complications and mortality should be reduced, and the patients' rehabilitation improved.

\section{Data collection}

The institutions following the model carried out a systematic compilation of clinical and process indicators in order to monitor the performance of the program. Each institution collected the following information:

- Demographic data: number of patients admitted, age, sex.

- Procedure variables: type of procedure.

- Variables of hospital stay: time from admission to surgery, time of pre-surgical stay, time of post-surgical stay, total time of stay.

- Follow-up outcome variables: in-hospital death, death in the first month after surgery, death in the first year after surgery, hospital readmission in the first 30 days after discharge.

- Intrahospital complications: delirium, pneumonia, urinary tract infection, surgical site, pressure ulcers, deep vein thrombosis, pulmonary thromboembolism, cardiovascular events, neurological events. 
This information was originally collected at the individual level. Each institution provided a monthby-month report summarizing the continuous variables with average and standard deviation (SD) and categorical variables such as event counts. These accumulated data were reported from the beginning of the program in each institution up until June 2018, including all patients included in the program. Since the institutions were integrated into the program at different times, the calendar year in which the institution was integrated into the Geriatric fracture programs was defined as the base year, and following years were defined as follow-up years.

\section{Data analysis}

Because the data came from different institutions, we performed a stratified description for each institution, with the objective of assessing possible systematic differences between them which could skew the grouped description. It is important to point out that the scope of this description was to view the trend in the indicators comparing the initial point of implementation against the last one available and did not include an explicit comparison between the institutions. Likewise, given the descriptive scope of the study and the absence of control of confounding variables, the trends should be interpreted only at the descriptive level and not in terms of causation. All procedures and graphs were performed using the statistical program R, version 3.5.0.

Initially, the number of patients treated in the institutions and their demographic characteristics were characterized, describing the trend of different types of hospital stay over time. These were calculated by hours and summarized using averages and SD. Subsequently, the complications registered in each institution were described, discriminating them by type of complication, and the trends of the outcome variables in the medium and long term. Considering the variability over time with respect to the total number of patients admitted to each institution, these results were expressed in terms of proportions. It was not possible to estimate the annual mortality rate for 2018 since the data were obtained in early 2019.

\section{Economic estimation}

A theoretical estimate was made of the possible economic impact of the program, focusing on the possible differences related to hospital stays and complications. This implies that surgical procedures costs were not considered. All costs were calculated in Colombian pesos and converted to United States dollars (USD) using the current exchange rate (1 USD $=3,301$ Colombian pesos). Clinical experts from the institutions were consulted for the construction of the resource consumption scenarios for the different complications. The costs of these events were estimated using the standard methodology of the Institute of Health Technological Assessment (IETS in Spanish). Costs were estimated from the perspective of the third-party payer, considering direct medical costs. Drug prices were obtained from the drug price information database (SISMED) of the last reported quarter and, where necessary, from the latest available regulated prices set by the Ministry of Health. Final drug prices were estimated as a weighted average by the market share of the average values recorded for each formulation. The costs of procedures were extracted from the tariff manual of the Social Security Institute in 2001, with an increase of $30 \%$ in accordance with the methodology proposed by IETS. Monetary values for the required consumables were consulted in the public tender documentation or in the Colombia Compra Eficiente database. For the hospital stay, a day-cost sensitivity analysis was performed, taking as a lower limit the cost of hospitalization of high complexity, and as an upper limit the cost of hospitalization in the adult intensive care unit. In this way the average price of the hospital stay was calculated, considering the observed lengths of stay from the institutions. Regarding complications, the estimated average cost per capita of all complications in the cohort of patients in the program was calculated from their proportions in each institution. By combining these two costs and viewing the trend over time, the average cost of the stay was estimated, plus the complication of a patient in the program. 
With this information, the costs associated with stay and complications for each institution in each year of implementation were estimated, and the baseline was compared with the last year available to estimate the variation in the cost associated with the stay and complications over time.

\section{Exploratory analyses}

Finally, in an exploratory manner, statistical comparisons were made between the first and last year of available data for total length of stay and number of complications. These analyses were hypothesis generating. For the time of stay a Student's t-test was performed to compare two unpaired samples assuming different variances. For complications, the comparison was made using the Z-test for two proportions.

\section{Compliance with ethical standards and ethical approval}

This study was approved by the Ethics Committee of the Santa Fe de Bogotá Foundation (Agreement No. 20 with the approval number CCEI-9941-2018 on November 19, 2018). It was thus conducted according to ethical standards applicable for this type of study. Under that protocol and approval, the study was performed in both institutions.

\section{Results}

\section{General description}

A total of 475 patients were identified between the two institutions. Institution A presented a total of three years of data with 190 patients (63.3 patients/year) and B a total of five years and 285 patients ( 57 patients/year). The main baseline characteristics of the patients identified are shown in Table 1. There was an increase in the total number of patients over the years of program implementation (A: from 55 to $71+29 \%$; B: from 44 to $77+75 \%$ ) in both institutions. Close to $78 \%$ of all patients were women, consistently across the institutions, and around $80 \%$ were older than 76 years. The procedure performed in most patients was nail osteosynthesis or compression device.

\section{Hospital length of stay}

The average total hospital length of stay had reductions between the base year throughout

Table 1. Demographic characteristics of the patients identified in the three institutions. The percentages are relative to the total of each institution.

\begin{tabular}{lrr} 
Variable & \multicolumn{2}{c}{ Institution } \\
\hline Total patients & $\mathbf{A ( \% )}$ & $\mathbf{B ( \% )}$ \\
\hline Patients according to year of implementation & & 285 \\
Base year & $55(28.9)$ & $44(15.4)$ \\
1 & $64(33.7)$ & $49(17.2)$ \\
2 & $71(37.4)$ & $56(19.6)$ \\
3 & $\mathrm{NA}(\mathrm{NA})$ & $59(20.7)$ \\
4 & $\mathrm{NA}(\mathrm{NA})$ & $77(27)$ \\
Patients by sex & & \\
Male & $41(21.6)$ & $64(22.5)$ \\
Female & $149(78.4)$ & $221(77.5)$ \\
Patients by age group (years) & & \\
$65-75$ & $45(23.7)$ & $51(17.9)$ \\
$76-85$ & $82(43.2)$ & $117(41.1)$ \\
$>85$ & $63(33.2)$ & $117(41.1)$ \\
Patients by procedure type & & \\
Osteosynthesis with nails or with compression device & $115(60.5)$ & $164(57.5)$ \\
Open reduction with osteosynthesis with cannulated screws & $10(5.3)$ & $27(9.5)$ \\
Joint replacement & $65(34.2)$ & $94(33)$ \\
\hline
\end{tabular}




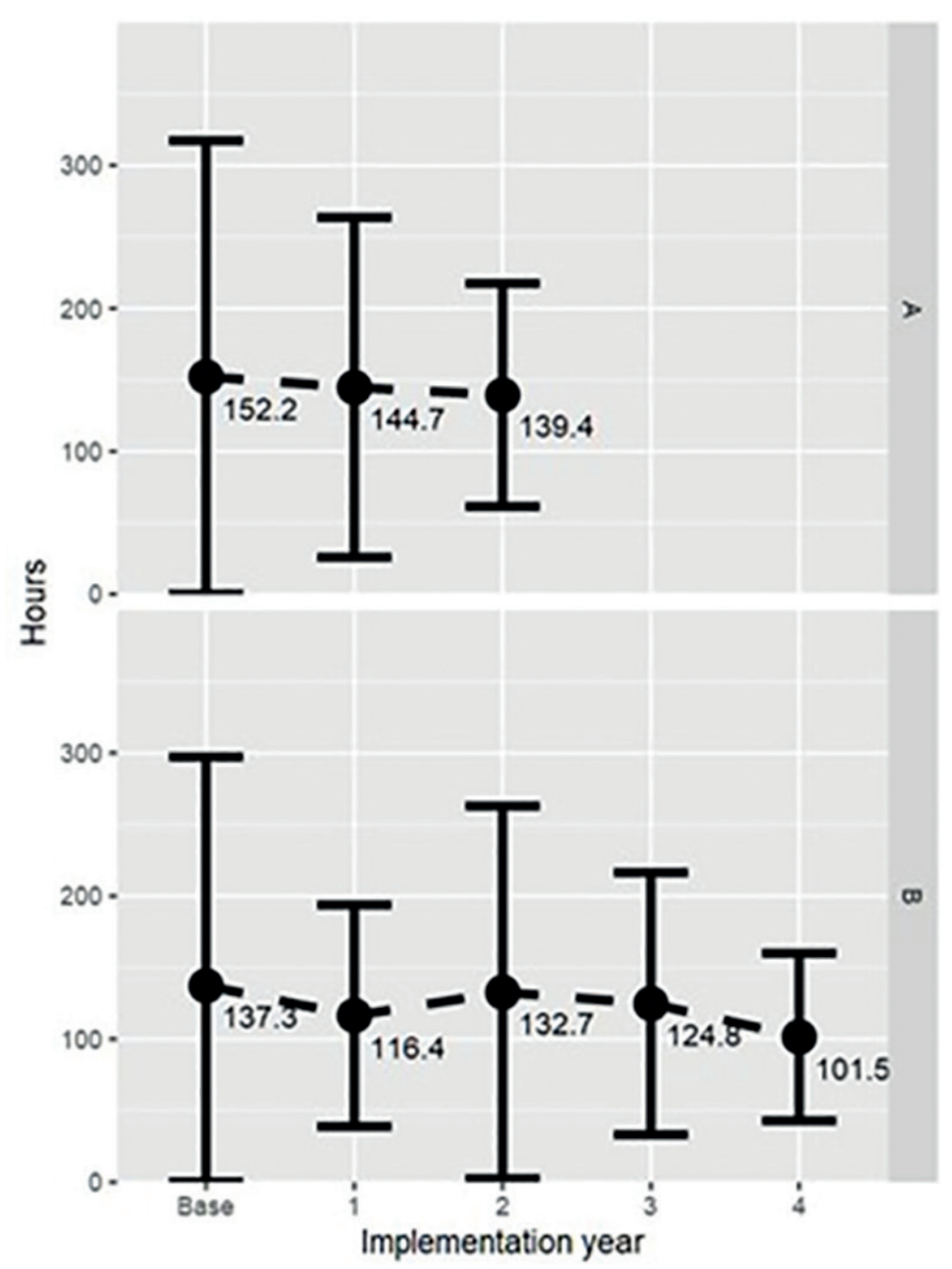

Figure 1. Average total hospital length of stay in hours, according to year of implementation and institution (A and $\mathrm{B})$. The error bars represent $\pm 1 \mathrm{SD}$

the implementation (Figure 1). When comparing the base year with the last available implementation year both institutions had reductions although of different magnitude (A: from 152.2 to 139.4, -8.5\%; B: from 137.3 to 101.5, -26.1\%). Institution B had a change between baseline and the second year of implementation of $-3.4 \%$, which was similar to the one achieved in institution $\mathrm{A}$ in the same timeframe.

When separating the total stay by type (admission-to-surgery, pre-surgical, post-surgical and total), it can be observed that there is a trend in reduction of the total and post-surgical hospital stay. In contrast, the pre-surgical stay remained relatively stable. This trend was similar in both institutions (Figure 2). In both institutions, the pre-surgical stay time was less than 48 hours.

\section{Complications}

The proportion of total complications was reduced in both institutions following the Geriatric fracture programs implementation (Figure 3). For institution A, the exploratory analysis found a difference of $-35.1 \%$ between the base year and the last year available, which was statistically significant $(74.5 \%$ vs. $39.4 \%, p<0.001,95 \%$ CI: $-52.9 \%$ to $-17.3 \%)$. For institution $\mathrm{B}$, the exploratory analysis found a difference of $-33.4 \%$ between the base year and the last year available, which was statistically significant ( $56.8 \%$ vs. $23.4 \%, p<0.001,95 \%$ CI: $-52.7 \%$ to $-14.2 \%)$. Table $1 \mathrm{~S}$ shows the details of the proportions of each type of complication over time. 


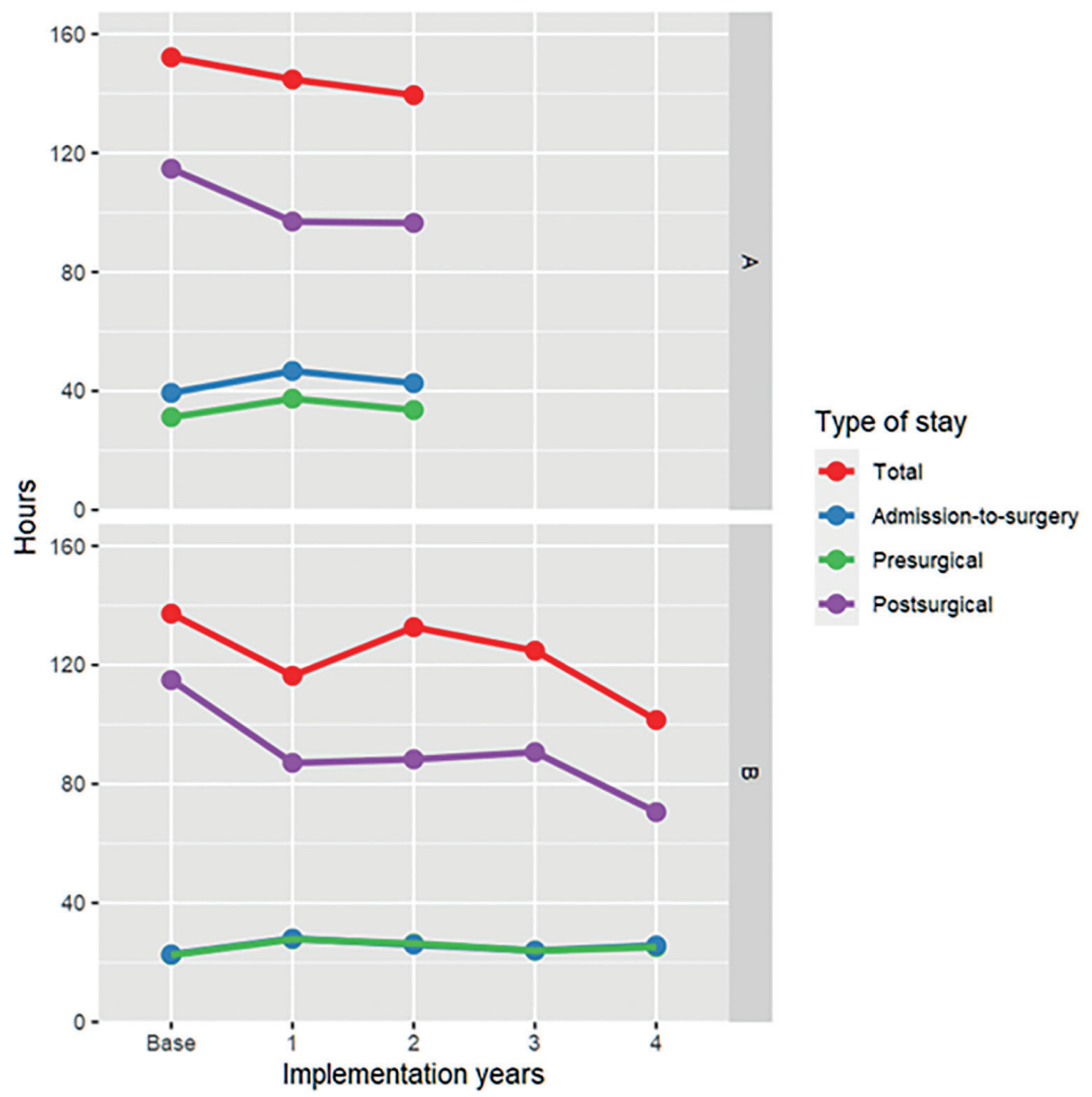

Figure 2. Average duration of the different times of stay in hours, according to year of implementation and institution $(\mathrm{A}$ and $\mathrm{B})$

By individually evaluating each institution, some differences in behavior can be observed. For institution $\mathrm{A}$, the reduction of total complications coincided with the reduction in pressure ulcers (from $3.6 \%$ to $1.6 \%$ ), cardiovascular events (from $12.7 \%$ to $1.4 \%$ ), surgical site infections (from $9.1 \%$ to $2.8 \%$ ), urinary tract infections (from 10.9 to $5.6 \%$ ), pneumonia (from $7.3 \%$ to $2.8 \%$ ) and pulmonary thromboembolism (from $10.9 \%$ to $1.4 \%$ ). In institution B, the decrease was mainly related to a decrease in the proportion of delirium (from $38.6 \%$ to $13 \%$ ), surgical site infections (from $2.3 \%$ to $1.7 \%$ ), urinary tract infection (from $4.5 \%$ to $2.6 \%$ ), pneumonia (6.8\% to $1.3 \%)$ and pressure ulcers ( $4.5 \%$ to $2.6 \%)$.

\section{Follow-up results}

In institution $\mathrm{A}$, lower proportions of patients were evident for all outcomes, when comparing the base year with the last available (readmissions from 14.5\% to 7\%, in-hospital deaths from $3.6 \%$ to $2.8 \%$, deaths within the first month of $1.8 \%$ to $1.4 \%$ and deaths within the first year from $10.9 \%$ to $4.7 \%$ ) (Figure 4 ). Regarding institution B, there was a trend towards a reduction in readmissions ( $18.2 \%$ vs. $15.6 \%)$, in-hospital deaths ( $4.5 \%$ vs. $2.6 \%)$ and deaths within the first year (11.4\% vs. 5.1\%). However, there was an increase in deaths within the first month ( $0 \%$ vs. $2.6 \%$ ), although no deaths were reported during the first observation (Figure 4 ). Detailed data is presented in Supplementary Table 2S.

\section{Estimation of health resources and costs}

In supplementary 3 Sand and $4 \mathrm{~S}, 4 \mathrm{~S}$, we report the estimation of health resources for each event of interest, made with the help of clinical experts. The estimated per-hospitalization-day and per-event costs are detailed in the supplementary Table 5. The individual complications with the highest estimated costs per event were pulmonary embolism (USD 3,891.6), cardiovascular 


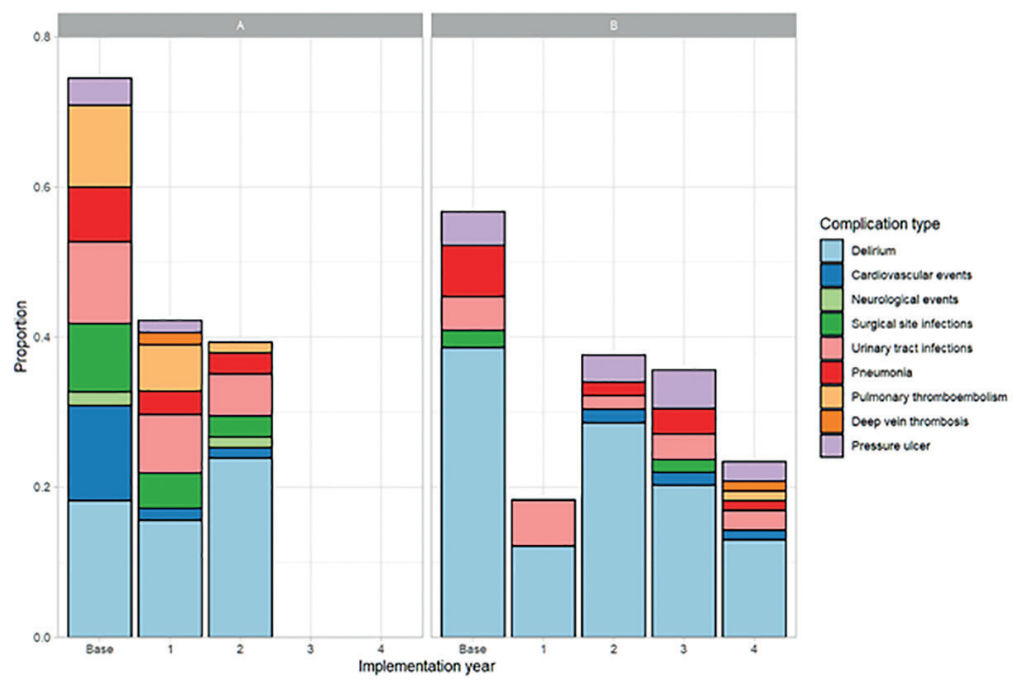

Figure 3. Proportion of patients with complications, by type of complication, by institution (A and $\mathrm{B}$ ) and year of implementation

event (USD 3,186.4) and pressure ulcers (USD 1,560.2). The ones with the lowest estimated cost were surgical site infection (USD 205.6), delirium (USD 276.5) and urinary tract infection (USD 485.9). There was also an important difference in the daily cost of stay between the lower and upper sensitivity scenarios (USD 22.1 vs USD 164.5).

The results of the estimated cost variations for hospital stay and complications are found in Table 2. Considering the duration and frequency of complications observed in the institutions, we estimated a general reduction in the costs associated with stay and complications throughout the implementation of the program. The absolute decrease in estimated costs related to stay and complications varied between USD 94 and USD 966. The relative variation ranged between $-22.0 \%$ and $-68.3 \%$. Similar results were observed in the cost differences considering only the stay or only complications, although the latter were generally of greater magnitude.

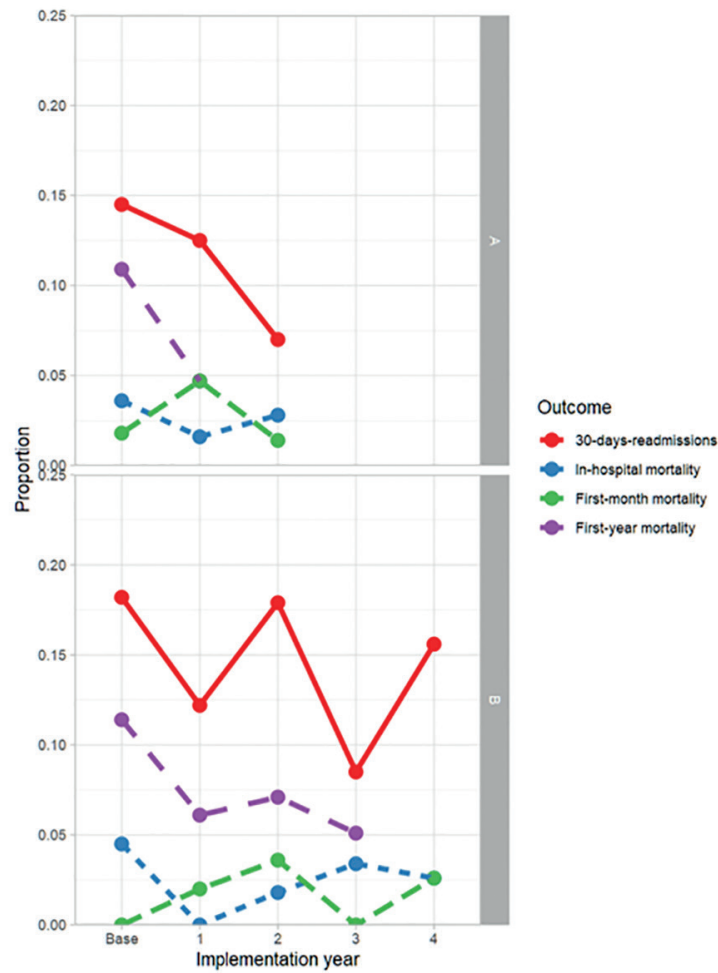

Figure 4. Proportion of patients with each type of outcome, according to institution $(\mathrm{A}$ and $\mathrm{B})$ and year of implementation 
Table 2. Estimated costs related to stay (with minimum and maximum sensitivity scenario), complications, and stay plus complications (with minimum and maximum sensitivity scenario) for each institution in each year of implementation. With these data, absolute and relative variations were calculated. NR $=$ not reported.

\begin{tabular}{|c|c|c|}
\hline \multirow{2}{*}{ Implementation year } & \multicolumn{2}{|c|}{ Institution } \\
\hline & $\mathbf{A}$ & $\mathbf{B}$ \\
\hline \multicolumn{3}{|c|}{ Hospital stay cost - minimum sensitivity scenario } \\
\hline Base & $\$ 182$ & $\$ 164$ \\
\hline 1 & $\$ 173$ & $\$ 139$ \\
\hline 2 & $\$ 167$ & $\$ 159$ \\
\hline 3 & NR & $\$ 149$ \\
\hline 4 & NR & $\$ 122$ \\
\hline Absolute variation & $-\$ 15$ & $-\$ 43$ \\
\hline Relative variation & $-8.4 \%$ & $-26.0 \%$ \\
\hline \multicolumn{3}{|c|}{ Hospital stay cost - maximum sensitivity scenario } \\
\hline Base & $\$ 1,356$ & $\$ 1,223$ \\
\hline 1 & $\$ 1,289$ & $\$ 1,037$ \\
\hline 2 & $\$ 1,242$ & $\$ 1,182$ \\
\hline 3 & NR & $\$ 1,112$ \\
\hline 4 & NR & $\$ 904$ \\
\hline Absolute variation & $-\$ 113$ & $-\$ 319$ \\
\hline Relative variation & $-8.4 \%$ & $-26.0 \%$ \\
\hline \multicolumn{3}{|l|}{ Cost of complications } \\
\hline Base & $\$ 1,089$ & $\$ 263$ \\
\hline 1 & $\$ 460$ & $\$ 63$ \\
\hline 2 & $\$ 237$ & $\$ 217$ \\
\hline 3 & NR & $\$ 240$ \\
\hline 4 & NR & $\$ 212$ \\
\hline Absolute variation & $-\$ 853$ & $-\$ 51$ \\
\hline Relative variation & $-78.3 \%$ & $-19.4 \%$ \\
\hline \multicolumn{3}{|c|}{ Average patient cost - minimum sensitivity scenario } \\
\hline Base & $\$ 1,271$ & $\$ 428$ \\
\hline 1 & $\$ 633$ & $\$ 203$ \\
\hline 2 & $\$ 404$ & $\$ 376$ \\
\hline 3 & NR & $\$ 389$ \\
\hline 4 & NR & $\$ 334$ \\
\hline Absolute variation & $-\$ 868$ & $-\$ 94$ \\
\hline Relative variation & $-68.3 \%$ & $-22.0 \%$ \\
\hline \multicolumn{3}{|c|}{ Average patient cost - maximum sensitivity scenario } \\
\hline Base & $\$ 2,445$ & $\$ 1,487$ \\
\hline 1 & $\$ 1,749$ & $\$ 1,100$ \\
\hline 2 & $\$ 1,479$ & $\$ 1,400$ \\
\hline 3 & NR & $\$ 1,352$ \\
\hline 4 & NR & $\$ 1,117$ \\
\hline Absolute variation & $-\$ 966$ & $-\$ 370$ \\
\hline Relative variation & $-39.5 \%$ & $-24.9 \%$ \\
\hline
\end{tabular}

\section{Discussion}

This study describes the experience of two Colombian healthcare institutions that have adopted the Geriatric fracture programs. This type of model seeks to achieve a comprehensive and multidisciplinary patient care program ${ }^{16}$. One of the priorities is to carry out the surgical procedure within the first 48 hours after the fracture. Longer presurgical time has been associated with a greater total length of stay, mortality and morbidity ${ }^{17}$. These experiences, along with the experience previously implemented and published in Colombia ${ }^{16}$, represent the first reports of experiences with these models in Latin America.

During the implementation of the model, trends are identified in the various measured indicators by comparing the base values with those present at the end of the observation.

Firstly, there is an increase in the number of patients treated, which may be relevant to the extent that it may signify a greater ability to offer these services. This is valuable in countries with problems of installed capacity for specialized services. 
A reduction in the length of stay was observed, particularly after surgery, and in the proportion of in-hospital complications. These reductions are desirable for patients and institutions and the health system in general. In the previously performed implementation ${ }^{16}$, a reduction in the time of stay was reported between the patients treated in the first two years of the program ( 5.3 days of stay on average) and those treated in the subsequent two years (3.42 days). Overall, it can be seen how the total length of stay is reduced during the Geriatric fracture programs, replicating the direction of the results previously obtained in Colombia.

Reductions in outcomes such as readmissions and deaths were also observed. Based on these data, the theoretical estimate of costs showed savings related to stays and complications during the program. In the implementation of the previously published Geriatric fracture programs, a reduction in mortality was found throughout the implementation (year 1:22.99\%, year 2: $16.22 \%$, year 3: $9.09 \%$, year $4: 12.68 \%$ ) that was statistically significant when comparing the first two years with the second two ${ }^{16}$. Therefore, the general outlook of the Geriatric fracture programs shows a trend towards the reduction in mortality and readmissions, which replicate the results achieved in previous implementations.

It is worth highlighting some interesting aspects. In general, similar trends were evidenced in both institutions. In addition, the institutions also registered decreases in the variance of the total stays, possibly indicating homogenization of these times. This point is very interesting, to the extent that it may reflect greater homogeneity in the health requirements of these patients.

Although the two institutions presented similar trends, there were some differences between them, both in the baseline indicators and in the magnitude of the changes seen during the implementation of the program. This is evident in the variations in the frequency of complications, which were very different in magnitude in each institution. This effect may be due to differences inherent in the institutions or to the patients treated. One possible explanation is that the impact of the Geriatric fracture programs is not complication-specific, but affects complications in general, obtaining different results according to the baseline of each institution. This hypothesis should be assessed in a later study.

Finally, these results replicated those previously seen for mortality and hospital stay in the first implementation, made more than 10 years ago with 298 patients treated over a period of 4 years ${ }^{16}$. This shows that GFPs can produce similar results in different institutions in Colombia. Replicating both the implementation and the results obtained is thus feasible in this context.

The trends seen in this characterization reflect some data seen in other studies. Two studies in the United States evaluated a similar program. They found that outcomes of hospital stay (between 4.2 and 4.6 days) and total cost of the event (USD 15,188) were substantially better than those shown in other cohorts presented in the literature ${ }^{11,14}$. Another comprehensive management program implemented in three institutions in the United States also showed a hospital stay reduction from 5.6 days in 826 patients before implementation to 4.7 days in 2,069 patients after implementation ${ }^{18}$. These results are consistent with the trends seen in the three institutions where the program has been implemented in Colombia.

The study displays some limitations derived from its design. Since it is an observational study, it is not possible to ensure complete control of the confounding variables. Thus, the observed variations in the indicators cannot be causally attributed to the Geriatric fracture programs. The descriptive nature of the study implies that the trends seen do not involve statistically significant changes and, when performed, the exploratory analyses are intended to generate hypotheses. The retrospective use of information collected routinely in institutions introduces the potential for information bias, particularly for measuring results that require external monitoring, such as mortality per year. Nevertheless, given that the institutions use this same information as an internal indicator, there are information verification processes that exist which help to alleviate this issue. All these aspects limit the extrapolation of the data but do not invalidate the observed results. 


\section{Conclusion}

The present study describes the experience of 475 patients treated in two institutions with the Geriatric fracture programs. Throughout the years of implementation, the institutions displayed an increase in number of patients treated, and decreases in length of stay, proportion of complications, proportion of readmissions, and deaths. The theoretical estimate of cost shows possible savings related to the reduction in stay and the proportion of complications. Results were generally similar between the two institutions. They are also very similar to other experiences of implementation in Colombia and at the international level. Both situations suggest that other institutions can replicate the program and its results at the national level.

\section{References}

1. Marks R. Hip fracture epidemiological trends, outcomes, and risk factors, 1970-2009. Int J Gen Med. 2010; 3: 1-17. DOI: 10.2147/ijgm.s5906

2. Mundi S, Pindiprolu B, Simunovic N, Bhandari M. Similar mortality rates in hip fracture patients over the past 31 years. Acta Orthop. 2014; 85(1): 54-9. . DOI: 10.3109/17453674.2013.878831

3. Lin KB, Yang NP, Lee YH, Chan CL, Wu CH, Chen HC, et al. The incidence and factors of hip fractures and subsequent morbidity in Taiwan: An 11-year population-based cohort study. PLoS One. 2018; 13(2):1-11. . DOI: 10.1371/journal.pone.0192388

4. Kanis JA, Odén A, McCloskey EV, Johansson H, Wahl DA, Cooper C. A systematic review of hip fracture incidence and probability of fracture worldwide. Osteoporos Int. 2012; 23(9): 2239-56. . DOI: 10.1007/s00198012-1964-3

5. Rapp K, Büchele G, Dreinhöfer K, Bücking B, Becker C, Benzinger P. Epidemiology of hip fractures: Systematic literature review of German data and an overview of the international literature. $Z$ Gerontol Geriatr. 2019; 52(1): 10-6. DOI: 10.1007/s00391-018-1382-z

6. Haentjens P, Magaziner J, Colón-Emeric CS, Vanderschueren D, Milisen K, Velkeniers B, et al. Metaanalysis: Excess mortality after hip fracture among older women and men. Ann Intern Med. 2010; 152(6): 38090. . DOI: 10.7326/0003-4819-152-6-201003160-00008

7. Aziziyeh R, Amin M, Habib M, Garcia Perlaza J, Szafranski K, McTavish RK, et al. The burden of osteoporosis in four Latin American countries: Brazil, Mexico, Colombia, and Argentina. J Med Econ. 2019; 22(7): 638-644. DOI: 10.1080/13696998.2019.1590843.

8. González LA, Vásquez GM, Molina JF. Epidemiología de la osteoporosis. Rev Colomb Reumatol. 2009; 16(1): 61-75. DOI: 10.1016/S0121-8123(09)70119-7

9. Titler M, Dochterman J, Kim T, Kanak M, Shever L, Picone DM, et al. Cost of care for seniors hospitalized for hip fracture and related procedures. Nurs Outlook. 2007;55(1):5-14. . DOI: 10.1016/j.outlook.2006.06.006

10. Burge R, Dawson-Hughes B, Solomon DH, Wong JB, King A, Tosteson A. Incidence and economic burden of osteoporosis-related fractures in the United States, 2005-2025. J Bone Miner Res. 2007; 22(3): 465-75. DOI: $10.1359 / \mathrm{jbmr} .061113$

11. Kates SL, Blake D, Bingham KW, Kates OS, Mendelson DA, Friedman SM. Comparison of an organized geriatric fracture program to united states government data. Geriatr Orthop Surg Rehabil. 2010; 1(1): 15-21. DOI: $10.1177 / 2151458510382231$

12. Kates SL, Mendelson DA, Friedman SM. Co-managed care for fragility hip fractures (Rochester model). Osteoporos Int. 2010; 21(Suppl 4): S621-5. . DOI: 10.1007/s00198-010-1417-9 
13. Friedman SM, Mendelson DA, Kates SL, McCann RM. Geriatric co-management of proximal femur fractures: total quality management and protocol-driven care result in better outcomes for a frail patient population. J Am Geriatr Soc. 2008; 56(7): 1349-56. . DOI: 10.1111/j.1532-5415.2008.01770.x

14. Kates SL, Malley NO, Friedman SM, Mendelson DA. Barriers to Implementation of an Organized Geriatric Fracture Program. Geriatr Orthop Surg Rehabil. 2012;3(1):8-16. . DOI: 10.1177/2151458512436423

15. Giusti A, Barone A, Razzano M, Pizzonia M, Pioli G. Optimal setting and care organization in the management of older adults with hip fracture. Eur J Phys Rehabil Med. 2011; 47(2):281-96.

16. Suarez S, Pesantez RF, Diaz ME, Sanchez D, Tristancho LJ, Vanegas MV, et al. Impact on hip fracture mortality after the establishment of an orthogeriatric care program in a colombian hospital. J Aging Health. 2017; 29(3): 474-88. DOI: 10.1177/0898264316636839

17. Bennett A, Li H, Patel A, Kang K, Gupta P, Choueka J, et al. Retrospective analysis of geriatric patients undergoing hip fracture surgery: delaying surgery is associated with increased morbidity, mortality, and length of stay. Geriatr Orthop Surg Rehabil. 2018; 9: 215145931879526. DOI: 10.1177/2151459318795260

18. Jackson K, Bachhuber M, Bowden D, Etter K, Tong C. Comprehensive hip fracture care program: successive implementation in 3 hospitals. Geriatr Orthop Surg Rehabil. 2019; 10. DOI: $10.1177 / 2151459319846057$ 


\section{Supplementary Material.}

Table 1S. Proportion of each type of complication, by institution and year of implementation.

\begin{tabular}{|c|c|c|c|c|}
\hline Variable & Year of implementation & Total & A & B \\
\hline \multirow[t]{5}{*}{ Number of patients with delirium } & Base & 0.273 & 0.182 & 0.386 \\
\hline & 1 & 0.142 & 0.156 & 0.122 \\
\hline & 2 & 0.26 & 0.239 & 0.286 \\
\hline & 3 & 0.203 & NR & 0.203 \\
\hline & 4 & 0.13 & NR & 0.13 \\
\hline \multirow[t]{5}{*}{ Number of patients with cardiovascular events } & Base & 0.071 & 0.127 & 0 \\
\hline & 1 & 0.009 & 0.016 & 0 \\
\hline & 2 & 0.016 & 0.014 & 0.018 \\
\hline & 3 & 0.017 & NR & 0.017 \\
\hline & 4 & 0.013 & NR & 0.013 \\
\hline \multirow[t]{5}{*}{ Number of patients with neurological events } & Base & 0.01 & 0.018 & 0 \\
\hline & 1 & 0 & 0 & 0 \\
\hline & 2 & 0.008 & 0.014 & 0 \\
\hline & 3 & 0 & NR & 0 \\
\hline & 4 & 0 & NR & 0 \\
\hline \multirow[t]{5}{*}{ Number of patients with surgical site infection } & Base & 0.061 & 0.091 & 0.023 \\
\hline & 1 & 0.027 & 0.047 & 0 \\
\hline & 2 & 0.016 & 0.028 & 0 \\
\hline & 3 & 0.017 & NR & 0.017 \\
\hline & 4 & 0 & NR & 0 \\
\hline \multirow[t]{5}{*}{ Number of patients with urinary tract infection } & Base & 0.081 & 0.109 & 0.045 \\
\hline & 1 & 0.071 & 0.078 & 0.061 \\
\hline & 2 & 0.039 & 0.056 & 0.018 \\
\hline & 3 & 0.034 & NR & 0.034 \\
\hline & 4 & 0.026 & NR & 0.026 \\
\hline \multirow[t]{5}{*}{ Number of patients with pneumonia } & Base & 0.071 & 0.073 & 0.068 \\
\hline & 1 & 0.018 & 0.031 & 0 \\
\hline & 2 & 0.024 & 0.028 & 0.018 \\
\hline & 3 & 0.034 & NR & 0.034 \\
\hline & 4 & 0.013 & NR & 0.013 \\
\hline \multirow[t]{5}{*}{ Number of patients with pulmonary thromboembolism } & Base & 0.061 & 0.109 & 0 \\
\hline & 1 & 0.035 & 0.062 & 0 \\
\hline & 2 & 0.008 & 0.014 & 0 \\
\hline & 3 & 0 & NR & 0 \\
\hline & 4 & 0.013 & NR & 0.013 \\
\hline \multirow[t]{5}{*}{ Number of patients with deep vein thrombosis } & Base & 0 & 0 & 0 \\
\hline & 1 & 0.009 & 0.016 & 0 \\
\hline & 2 & 0 & 0 & 0 \\
\hline & 3 & 0 & NR & 0 \\
\hline & 4 & 0.013 & NR & 0.013 \\
\hline \multirow[t]{5}{*}{ Number of patients with pressure ulcers } & Base & 0.04 & 0.036 & 0.045 \\
\hline & 1 & 0.009 & 0.016 & 0 \\
\hline & 2 & 0.016 & 0 & 0.036 \\
\hline & 3 & 0.051 & NR & 0.051 \\
\hline & 4 & 0.026 & NR & 0.026 \\
\hline
\end{tabular}


Table 2S. Proportion of patients achieving each type of outcome, according to institution and year of implementation.

\begin{tabular}{|c|c|c|c|c|}
\hline & & & itutior & \\
\hline Variable & Year of implementation & Total & A & $\mathrm{B}$ \\
\hline 30-days-readmissions & Base & 0.162 & 0.145 & 0.182 \\
\hline & 1 & 0.124 & 0.125 & 0.122 \\
\hline & 2 & 0.118 & 0.07 & 0.179 \\
\hline & 3 & 0.085 & NR & 0.085 \\
\hline & 4 & 0.156 & NR & 0.156 \\
\hline In-hospital mortality & Base & 0.04 & 0.036 & 0.045 \\
\hline & 1 & 0.009 & 0.016 & 0 \\
\hline & 2 & 0.024 & 0.028 & 0.018 \\
\hline & 3 & 0.034 & NR & 0.034 \\
\hline & 4 & 0.026 & NR & 0.026 \\
\hline First-month-mortality & Base & 0.01 & 0.018 & 0 \\
\hline & 1 & 0.035 & 0.047 & 0.02 \\
\hline & 2 & 0.024 & 0.014 & 0.036 \\
\hline & 3 & 0 & NR & 0 \\
\hline & 4 & 0.026 & NR & 0.026 \\
\hline First-year-mortality & Base & 0.111 & 0.109 & 0.114 \\
\hline & 1 & 0.053 & 0.047 & 0.061 \\
\hline & 2 & 0.055 & NR & 0.071 \\
\hline & 3 & 0.051 & NR & 0.051 \\
\hline & 4 & NR & NR & NR \\
\hline
\end{tabular}


Table 3S. Estimated resources for hospitalization and complication for each event, with prices in USD.

\begin{tabular}{|c|c|c|c|c|c|}
\hline & & $\begin{array}{c}\text { Unitar } \\
\text { Price (USD) }\end{array}$ & & & \\
\hline$\overline{\mathrm{S} 11303}$ & Ward hospitalization - 3 beds - high complexity & 22.1 & & & \\
\hline S12103 & Adult intensive care unit & 164.5 & & & \\
\hline CUPS & Laboratories, consultations, procedures & 5.5 & Number & $\%$ Patients & \\
\hline 890702 & Emergency consultation, specialized medicine & 3.3 & 8 & 100 & \\
\hline 902210 & Type IV hemogram & 3.8 & 3 & 100 & \\
\hline 903839 & Arterial blood gases & 0.9 & 2 & 100 & \\
\hline 903825 & Creatinine in the blood & 80.4 & 4 & 100 & \\
\hline 901314 & Mycobacterium, identification by PCR & 6.3 & 2 & 50 & \\
\hline 871121 & Chest X-ray & 2.5 & 2 & 100 & \\
\hline 939400 & Respiratory therapy & 33.6 & 40 & 100 & \\
\hline 879301 & Chest CT scan & 5.5 & 1 & 100 & \\
\hline \multirow[t]{15}{*}{ CUPS } & Medications & & Daily dose & \# days & $\%$ Patients \\
\hline & Sultamicillin, taken orally 375 mg (\# tab/day) & & 750 & 7 & 40 \\
\hline & Clarithromycin, taken orally (mg/day) & & 1000 & 7 & 70 \\
\hline & Oxygen (L/day) & & 4320 & 7 & 60 \\
\hline & Ampicillin + Sulbactam, intravenous (g/day) & & 12 & 10 & 60 \\
\hline & Clarithromycin, intravenous (mg/day) & & 1000 & 7 & 70 \\
\hline & Paracetamol, taken orally (mg/day) & & 3000 & 7 & 80 \\
\hline & Omeprazole, taken orally (mg/day) & & 40 & 7 & 100 \\
\hline & Enoxaparin subcutaneous (mg/day) & & 40 & 7 & 100 \\
\hline & Ipratropium bromide inhaler (puff/day) & & 8 & 7 & 80 \\
\hline & Cefepime, intravenous (mg/day) & & 3000 & 10 & 30 \\
\hline & Piperacillin - Tazobactam, intravenous (mg/day) & & 18000 & 10 & 40 \\
\hline & Methylprednisolone, intravenous (mg/day) & & 375 & 5 & 50 \\
\hline & & & Ward (\%) & ICU (\%) & \\
\hline & $\begin{array}{l}\text { In what percentage of patients is hospitalization required for care regarding } \\
\text { the event? }\end{array}$ & & 80 & 20 & \\
\hline \multirow[t]{2}{*}{ CUPS } & & ISS 2001 & Ward & ICU & \\
\hline & Of those hospitalized, what is the average duration of their stay (days)? & & 7 & 5 & \\
\hline CUPS & Laboratories, consultations, procedures & ISS 2001 & Number & $\%$ Patients & \\
\hline 890702 & Emergency consultation, specialized medicine & 5.5 & 9 & 100 & \\
\hline 902210 & Type IV hemogram & 3.3 & 2 & 100 & \\
\hline 903825 & Creatinine in the blood & 0.9 & 2 & 100 & \\
\hline 903856 & BUN in the blood & 1.1 & 2 & 100 & \\
\hline 903703 & Vitamin B12 [Cyanocobalamin] & 9.9 & 1 & 100 & \\
\hline 903706 & Vitamin D25 Hydroxy Total [D2-D3] [Calciferol] & 13.8 & 1 & 100 & \\
\hline 904902 & TSH & 7.3 & 1 & 100 & \\
\hline 903864 & Sodium in the blood & 1.8 & 1 & 100 & \\
\hline 903859 & Potassium in the blood & 2.5 & 1 & 100 & \\
\hline 871121 & $\begin{array}{l}\text { Chest X-ray (PA or AP and lateral, lateral decubitus, oblique or lateral with } \\
\text { barium) }\end{array}$ & 6.3 & 1 & 100 & \\
\hline 907107 & Urine test & 1.1 & 1 & 100 & \\
\hline 879111 & Brain CT & 29.4 & 1 & 70 & \\
\hline \multirow[t]{6}{*}{ CUPS } & Medications & & Daily dose & \# days & $\%$ Patients \\
\hline & Haloperidol, taken orally (mg/day) & & 3 & 5 & 70 \\
\hline & Quetiapine, taken orally (mg/day) & & 100 & 5 & 50 \\
\hline & Olanzapine, taken orally (mg/day) & & 10 & 5 & 30 \\
\hline & & & Ward & ICU & \\
\hline & $\begin{array}{l}\text { In what percentage of patients is hospitalization required for care regarding } \\
\text { the event? }\end{array}$ & & $80 \%$ & $0 \%$ & \\
\hline \multirow[t]{2}{*}{ CUPS } & & ISS 2001 & Ward & ICU & \\
\hline & Of those hospitalized, what is the average duration of their stay (days)? & & 5 & 0 & \\
\hline CUPS & Laboratories, consultations, procedures & ISS 2001 & Number & $\%$ Patients & \\
\hline 890702 & Emergency consultation, specialized medicine & 5.5 & 6 & 100 & \\
\hline 902210 & Type IV hemogram & 3.3 & 2 & 100 & \\
\hline 903825 & Creatinine in the blood & 0.9 & 2 & 60 & \\
\hline 901221 & Blood culture & 9.2 & 2 & 100 & \\
\hline 881332 & Ultrasound of urinary tract & 9.1 & 1 & 100 & \\
\hline 907107 & Urine test & 1.1 & 1 & 100 & \\
\hline 901236 & Urine culture & 8.8 & 1 & 100 & \\
\hline 550401 & Percutaneous nephrostomy & 75.6 & 1 & 10 & \\
\hline 879420 & CT urography & 40.3 & 1 & 30 & \\
\hline
\end{tabular}




\begin{tabular}{|c|c|c|c|c|c|}
\hline & & $\begin{array}{c}\text { Unitar } \\
\text { Price (USD) }\end{array}$ & & & \\
\hline \multirow[t]{9}{*}{$\overline{\text { CUPS }}$} & Medications & & Daily dose & \# days & \% Patients \\
\hline & Ampicillin + Sulbactam, intravenous (g/day) & & 12 & 7 & 10 \\
\hline & Ceftriaxone, intravenous (mg/day) & & 2000 & 7 & 80 \\
\hline & Piperacillin - Tazobactam, intravenous (mg/day) & & 18000 & 10 & 4 \\
\hline & Ciprofloxacin, intravenous (mg/day) & & 800 & 7 & 1 \\
\hline & Ertapenem, intravenous (g/day) & & 1 & 10 & 2 \\
\hline & Meropenem, intravenous (mg/day) & & 3000 & 10 & 3 \\
\hline & & & Ward & ICU & \\
\hline & $\begin{array}{l}\text { In what percentage of patients is hospitalization required for care regarding } \\
\text { the event? }\end{array}$ & & $90 \%$ & $10 \%$ & \\
\hline CUPS & Of those hospitalized, what is the average duration of their stay (days)? & ISS 2001 & $\begin{array}{c}\text { Ward } \\
5\end{array}$ & $\begin{array}{r}\text { ICU } \\
10\end{array}$ & \\
\hline CUPS & Laboratories, consultations, procedures & ISS 2001 & Number & $\%$ Patients & \\
\hline 890702 & Emergency consultation, specialized medicine & 5.5 & 1 & 70 & \\
\hline 902210 & Type IV hemogram & 3.3 & 1 & 100 & \\
\hline 906913 & Automated high precision C-reactive protein test & 4.7 & 1 & 100 & \\
\hline 902205 & Automated erythrocyte sedimentation rate (ESR) & 0.4 & 1 & 100 & \\
\hline 862803 & $\begin{array}{l}\text { Non-excisional debridement of devitalized tissue, between } 10 \% \text { and } 20 \% \text { of } \\
\text { body surface }\end{array}$ & 0.0 & 1 & 30 & \\
\hline S23202 & Treatment - S23202 & 16.8 & & & \\
\hline S41101 & Surgical or gyneco-obstetric clinical specialists & 0.4 & & & \\
\hline S41201 & Anesthesiology specialists & 0.3 & & & \\
\hline S41301 & Surgical assistant & 0.1 & & & \\
\hline S55104 & Suture material & 13.7 & & & \\
\hline 901217 & $\begin{array}{l}\text { Microorganism culture in any sample other than bone marrow, urine and } \\
\text { feces (\#2) }\end{array}$ & 4.3 & 1 & 100 & \\
\hline 901209 & Sample of intrasurgical cultures & 3.8 & 1 & 100 & \\
\hline 901107 & Gram staining and reading for any sample & 0.9 & 1 & 100 & \\
\hline \multirow[t]{6}{*}{ CUPS } & Medications & & Daily dose & \# days & \% Patients \\
\hline & Cefalexin, taken orally (mg/day) & & 4000 & 7 & 70 \\
\hline & Amikacin, intravenous (mg/day) & & 500 & 7 & 30 \\
\hline & Paracetamol, taken orally (mg/day) & & 1500 & 3 & 70 \\
\hline & & & Ward & ICU & \\
\hline & $\begin{array}{l}\text { In what percentage of patients is hospitalization required for care regarding } \\
\text { the event? }\end{array}$ & & $100 \%$ & $0 \%$ & \\
\hline \multirow[t]{2}{*}{ CUPS } & & ISS 2001 & Ward & ICU & \\
\hline & Of those hospitalized, what is the average duration of their stay (days)? & & 2 & 0 & \\
\hline CUPS & Laboratories, consultations, procedures & ISS 2001 & Number & $\%$ Patients & \\
\hline 890702 & Emergency consultation, specialized medicine & 5.5 & 8 & 70 & \\
\hline 902210 & Type IV hemogram & 3.3 & 3 & 100 & \\
\hline 906913 & Automated high precision C-reactive protein test & 4.7 & 2 & 100 & \\
\hline 902205 & Automated erythrocyte sedimentation rate (ESR) & 0.4 & 2 & 100 & \\
\hline 862803 & $\begin{array}{l}\text { Non-excisional debridement of devitalized tissue, between } 10 \% \text { and } 20 \% \text { of } \\
\text { body surface }\end{array}$ & 0.0 & 2 & 100 & \\
\hline 901217 & $\begin{array}{l}\text { Microorganism culture in any sample other than bone marrow, urine and } \\
\text { feces (\#2) }\end{array}$ & 4.3 & 2 & 100 & \\
\hline 901209 & Sample of intrasurgical cultures & 3.8 & 2 & 100 & \\
\hline 901107 & Gram staining and reading for any sample & 0.9 & 2 & 100 & \\
\hline 862601 & Debridement with placement of subatmospheric pressure device & 552.1 & 1 & 100 & \\
\hline 862602 & Subatmospheric pressure device replacement & 318.5 & 7 & 100 & \\
\hline $965902 \mathrm{C}$ & Enterostomal therapy (wound care) & 2.0 & 8 & 100 & \\
\hline \multirow[t]{7}{*}{ CUPS } & Medications & & Daily dose & \# days & \% Patients \\
\hline & Ampicillin + Sulbactam, intravenous (g/day) & & 12 & 7 & 1 \\
\hline & Zinc oxide ( $30 \mathrm{~g}$ of active agent) & & 1 & 1 & 60 \\
\hline & Collagenase 120 UI (40 g) & & 1 & 1 & 10 \\
\hline & Hydrocolloid dressing & 8.7 & 1 & 1 & 10 \\
\hline & Saline solution & & 250 & 1 & 90 \\
\hline & $\begin{array}{l}\text { In what percentage of patients is hospitalization required for care regarding } \\
\text { the event? }\end{array}$ & & $90 \%$ & $10 \%$ & \\
\hline CUPS & Of those hospitalized, what is the average duration of their stay (days)? & ISS 2001 & $\begin{array}{c}\text { Ward } \\
15\end{array}$ & $\begin{array}{r}\text { ICU } \\
0\end{array}$ & \\
\hline
\end{tabular}




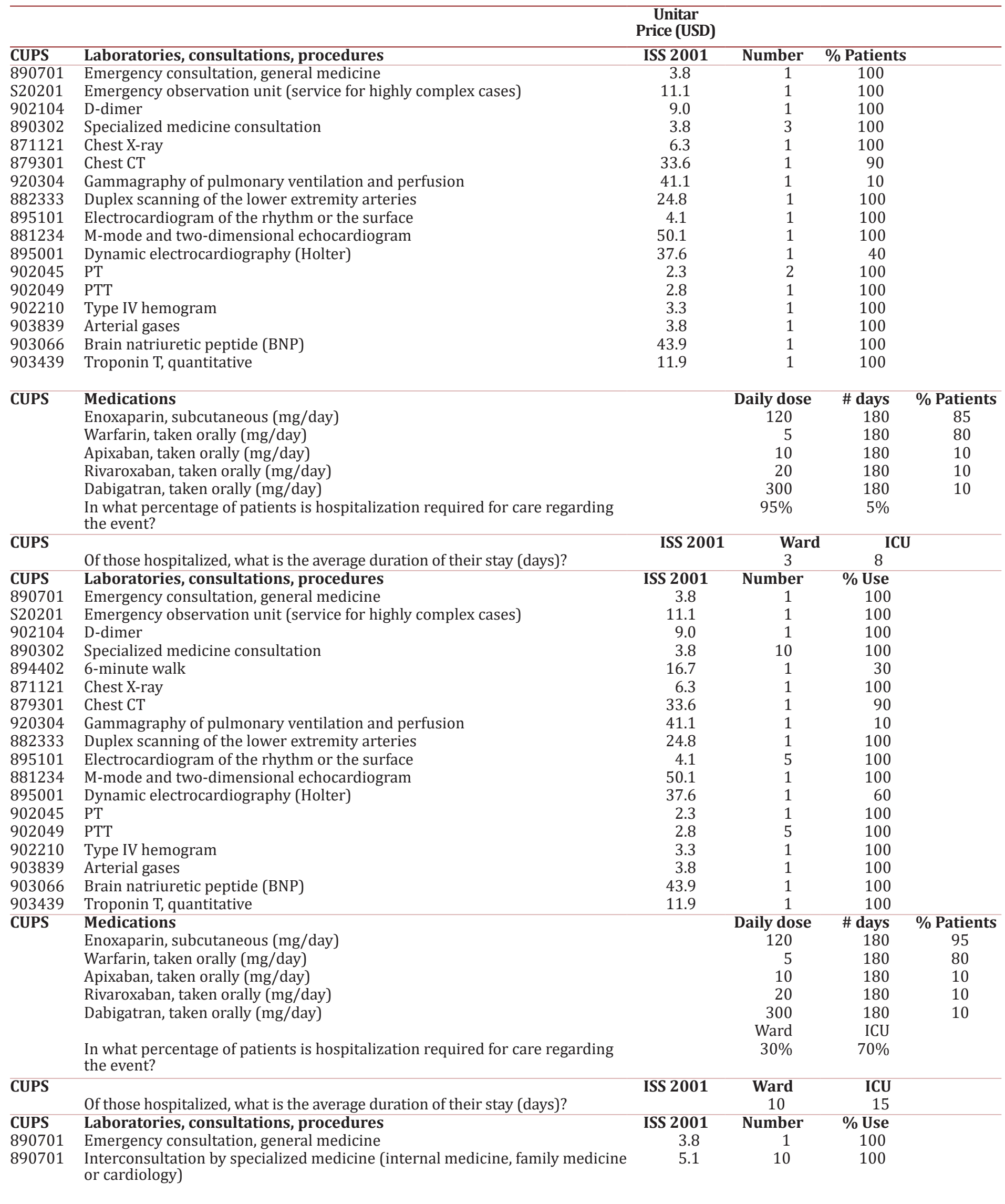




\begin{tabular}{|c|c|c|c|c|c|}
\hline & & $\begin{array}{c}\text { Unitar } \\
\text { Price (USD) }\end{array}$ & & & \\
\hline$\overline{903426}$ & Glycated hemoglobin & 5.9 & 1 & 100 & \\
\hline 903818 & Total cholesterol & 1.3 & 1 & 100 & \\
\hline 903815 & HDL cholesterol & 1.7 & 1 & 100 & \\
\hline 903816 & LDL cholesterol & 1.7 & 1 & 100 & \\
\hline 903868 & Triglycerides & 1.6 & 1 & 100 & \\
\hline 895101 & Electrocardiogram & 4.1 & 10 & 100 & \\
\hline 881232 & Transthoracic echocardiogram (M-mode and two-dimensional) & 24.9 & 1 & 100 & \\
\hline 372301 & $\begin{array}{l}\text { Cardiac catheterization of the right and left sides of the heart with electrophy- } \\
\text { siological study }\end{array}$ & 227.0 & 1 & 100 & \\
\hline C40558 & Coronary angioplasty with balloon & $1,378.2$ & 1 & 60 & \\
\hline & Medicated stent & & 1 & 100 & \\
\hline 871121 & Chest X-ray & 6.3 & 1 & 100 & \\
\hline 903841 & Glycemia & 0.9 & 10 & 100 & \\
\hline 902045 & PT & 2.3 & 5 & 100 & \\
\hline 902049 & PTT & 2.8 & 5 & 100 & \\
\hline 903439 & Troponin T & 11.9 & 5 & 100 & \\
\hline 904902 & Thyroid stimulating hormone (TSH) & 7.3 & 1 & 100 & \\
\hline 903825 & Creatinine in the blood & 0.9 & 4 & 100 & \\
\hline 903856 & Blood urea nitrogen (BUN) & 1.1 & 4 & 100 & \\
\hline 907107 & Urinary sediment and density analysis & 1.1 & 2 & 100 & \\
\hline 902210 & Type IV hemogram & 3.3 & 3 & 100 & \\
\hline 933600 & Cardiac rehabilitation therapy & 5.9 & 10 & 100 & \\
\hline CUPS & Medications & & Daily dose & \# days & $\%$ Patients \\
\hline & Losartan, taken orally (mg/day) & & 100 & 10 & 90 \\
\hline & Metoprolol tartrate, taken orally (mg/day) & & 300 & 10 & 50 \\
\hline & Atorvastatin, taken orally (mg/day) & & 80 & 10 & 100 \\
\hline & Aspirin, taken orally (mg/day) & & 100 & 10 & 100 \\
\hline & Clopidogrel, taken orally (mg/day) & & 75 & 10 & 100 \\
\hline & Oxygen (L/day) & & 4320 & 5 & 100 \\
\hline & Morphine, intravenous (mg/day) & & 10 & 5 & 70 \\
\hline & Metoclopramide, taken orally (mg/day) & & 30 & 5 & 50 \\
\hline & Bisacodyl, taken orally (mg/day) & & 10 & 10 & 100 \\
\hline & Nitroglycerine, intravenous (mg/day) & & 50 & 3 & 100 \\
\hline & Carvedilol, taken orally (mg/day) & & 25 & 10 & 20 \\
\hline & Bisoprolol, taken orally (mg/day) & & 10 & 10 & 30 \\
\hline & & & Ward & ICU & \\
\hline & $\begin{array}{l}\text { In what percentage of patients is hospitalization required for care regarding } \\
\text { the event? }\end{array}$ & & $10 \%$ & $90 \%$ & \\
\hline CUPS & & ISS 2001 & Ward & ICU & \\
\hline & Of those hospitalized, what is the average duration of their stay (days)? & & 5 & 7 & \\
\hline CUPS & Laboratories, consultations, procedures & ISS 2001 & Number & $\%$ Use & \\
\hline 890701 & Emergency consultation, general medicine & 3.8 & 1 & 100 & \\
\hline 890701 & $\begin{array}{l}\text { Interconsultation by specialized medicine (internal medicine, family medicine } \\
\text { or neurology) }\end{array}$ & 5.1 & 10 & 100 & \\
\hline 903426 & Glycated hemoglobin & 5.9 & 1 & 100 & \\
\hline 903818 & Total cholesterol & 1.3 & 1 & 100 & \\
\hline 903815 & HDL cholesterol & 1.7 & 1 & 100 & \\
\hline 903816 & LDL cholesterol & 1.7 & 1 & 100 & \\
\hline 903868 & Triglycerides & 1.6 & 1 & 100 & \\
\hline 903841 & Glycemia & 0.9 & 7 & 100 & \\
\hline 902045 & PT & 2.3 & 3 & 100 & \\
\hline 902049 & PTT & 2.8 & 3 & 100 & \\
\hline 903439 & Troponin T & 11.9 & 1 & 100 & \\
\hline 904902 & Thyroid stimulating hormone (TSH) & 7.3 & 1 & 100 & \\
\hline 903825 & Creatinine in the blood & 0.9 & 2 & 100 & \\
\hline 903856 & Blood urea nitrogen (BUN) & 1.1 & 2 & 100 & \\
\hline 907107 & Urinary sediment and density analysis & 1.1 & 2 & 90 & \\
\hline 903605 & Ionogram (chlorine, sodium, potassium and bicarbonate or calcium) & 6.6 & 3 & 100 & \\
\hline 902210 & Type IV hemogram & 3.3 & 2 & 100 & \\
\hline 902109 & Glucose-6-phosphate dehydrogenase, quantitative & 8.1 & 1 & 20 & \\
\hline 895101 & Electrocardiogram & 4.1 & 1 & 100 & \\
\hline 881232 & Transthoracic echocardiogram (M-mode and two-dimensional) & 24.9 & 1 & 100 & \\
\hline 881233 & Echocardiogram, M-mode and two-dimensional with Doppler & 39.2 & 1 & 100 & \\
\hline
\end{tabular}




\begin{tabular}{|c|c|c|c|c|c|}
\hline & & $\begin{array}{c}\text { Unitar } \\
\text { Price (USD) }\end{array}$ & & & \\
\hline 881235 & Transoesophageal echocardiogram & 63.7 & 1 & 50 & \\
\hline 871121 & Chest X-ray & 6.3 & 1 & 100 & \\
\hline 879111 & Brain CAT & 29.4 & 1 & 100 & \\
\hline 882110 & Carotid Doppler test (vertebral arteries and jugular vein) & 21.1 & 1 & 100 & \\
\hline 883101 & Nuclear magnetic resonance of the brain & 80.6 & 1 & 100 & \\
\hline 931000 & Complete physical therapy & 3.9 & 7 & 100 & \\
\hline 938300 & Complete occupational therapy & 1.8 & 5 & 100 & \\
\hline 937000 & Complete phonoaudiological therapy & 1.8 & 5 & 100 & \\
\hline S41501 & $\begin{array}{l}\text { Daily enteral or parenteral nutritional management of the hospitalized pa- } \\
\text { tient }\end{array}$ & 1.2 & 3 & 100 & \\
\hline \multirow[t]{13}{*}{ CUPS } & Medications & & Daily dose & \# days & \% Patients \\
\hline & Losartan, taken orally (mg/day) & & 100 & 8 & 90 \\
\hline & Metoprolol tartrate, taken orally (mg/day) & & 300 & 8 & 50 \\
\hline & Atorvastatin, taken orally (mg/day) & & 80 & 8 & 90 \\
\hline & Aspirin, taken orally (mg/day) & & 100 & 8 & 100 \\
\hline & Clopidogrel, taken orally (mg/day) & & 75 & 8 & 100 \\
\hline & Oxygen (L/day) & & 4320 & 5 & 100 \\
\hline & Bisoprolol, taken orally (mg/day) & & 10 & 8 & 30 \\
\hline & Carvedilol, taken orally (mg/day) & & 25 & 8 & 20 \\
\hline & Enalapril, taken orally (mg/day) & & 40 & 8 & 10 \\
\hline & Enoxaparin, subcutaneous (mg/day) & & 120 & 8 & 50 \\
\hline & & & Ward & ICU & \\
\hline & $\begin{array}{l}\text { In what percentage of patients is hospitalization required for care regarding } \\
\text { the event? }\end{array}$ & & $50 \%$ & $50 \%$ & \\
\hline CUPS & Of those hospitalized, what is the average duration of their stay (days)? & ISS 2001 & $\begin{array}{r}\text { Ward } \\
5\end{array}$ & $\begin{array}{r}\text { ICU } \\
3\end{array}$ & \\
\hline
\end{tabular}

Table 4S. Per-event and per-day estimated costs in USD for hospitalization and complications

\begin{tabular}{lc}
\hline Event & Average \\
\hline Pneumonia/event & $\$ 882.0$ \\
Delirium/event & $\$ 276.5$ \\
Urinary tract infection/event & $\$ 485.9$ \\
Surgical site infection/event & $\$ 205.6$ \\
Pressure ulcers/event & $\$ 1,560.2$ \\
Deep vein thrombosis/event & $\$ 1,519.9$ \\
Pulmonary embolism/event & $\$ 3,891.6$ \\
Cardiovascular event/event & $\$ 3,186.4$ \\
Neurological event/event & $\$ 986.9$ \\
Hospitalization floor - high complexity/ day & $\$ 22.1$ \\
Adult intensive care unit/day & $\$ 164.5$ \\
\hline
\end{tabular}




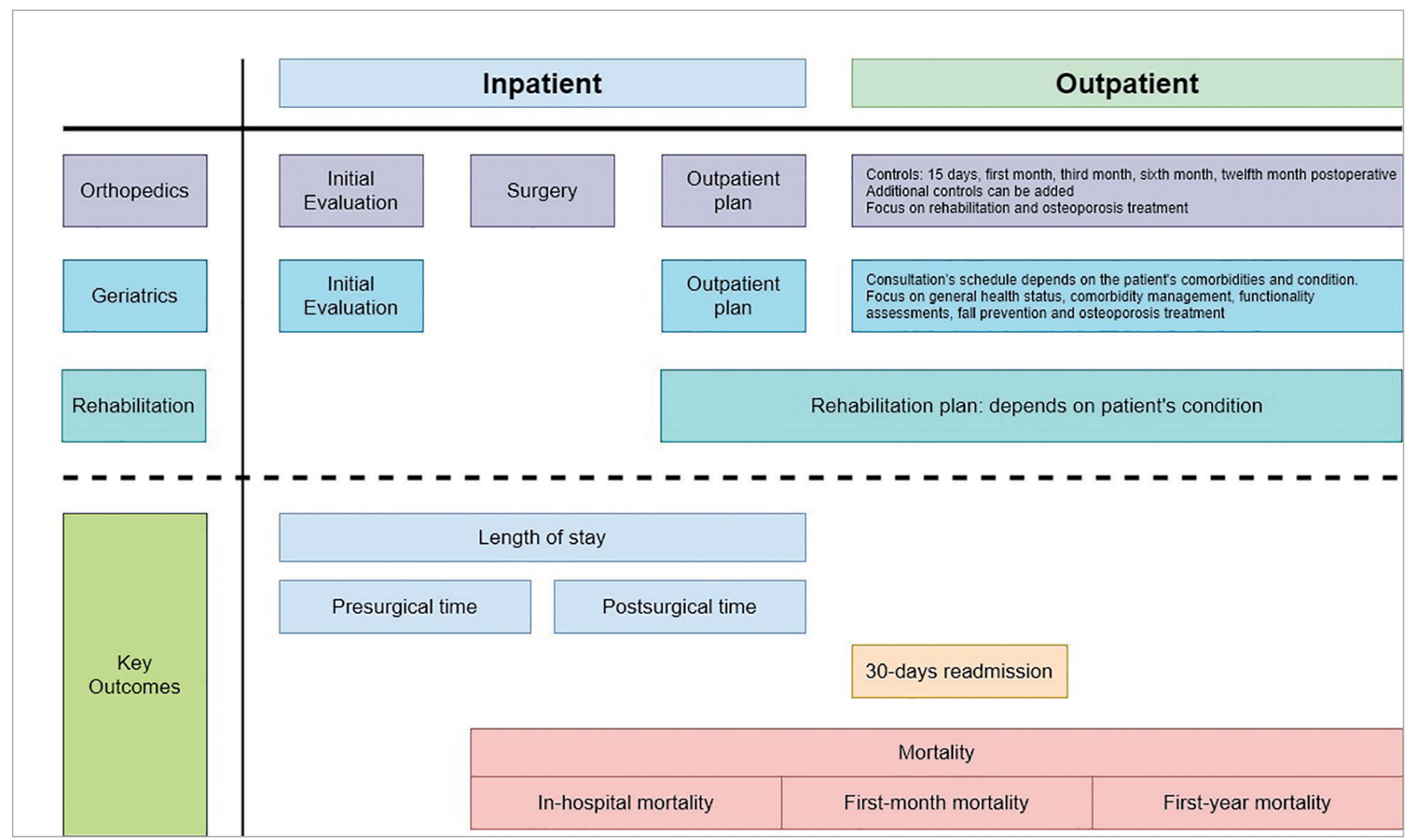

Figure S1. The program considered two components. One was related to inpatient care. The second component considered outpatient care during the first postsurgical year 